\title{
Planning and Design for Templeton
}

\author{
Emily Gerger
}

Senior, BCRP, Cal Poly.

\begin{abstract}
Concept plans for the whole town of Templeton, CA as well as for the Ramada Drive and the Downtown areas were developed by the two-quarter-long senior-year planning studio. Emily Gerger, one of the students in the studio, describes the class work which included intensive surveys and public workshops. Working under the leadership of instructor Zelika Howard, their client was the San Luis Obispo County Planning Department.
\end{abstract}

\begin{abstract}
In September 2012, the fourth year Community Planning Lab partnered with the San Luis Obispo County Planning and Building Department to prepare planning and design studies for Templeton, California. The class of 20 students conducted extensive background research and community outreach, and prepared proposals for future development for the overall community and three opportunity areas. The information and recommendations contained in the final reports are intended to assist the county's Planning Department in the process of updating the Templeton Community Plan.
\end{abstract}

The purpose of the class efforts was to identify, develop, and share a planning vision for the future of the Templeton community. The three opportunity areas that were more closely analyzed included the Downtown, the Ramada Drive, and an expansion area outside the Urban Reserve Line. The selection of these opportunity areas, as well as the final concept plans for them, resulted from extensive community outreach conducted by the class: two community workshops, one workshop with high school students, online and on-site surveys, stakeholder interviews, and a focus group workshop. The final products consisted of four reports: concept proposals and development strategies for future development in each opportunity area and a public outreach report detailing community engagement.

\section{Project Location}

Templeton, California, is a rural unincorporated community of 7,574 residents located in northern San Luis Obispo County, in the heart of the wine country. As the site of the last stop on the Southern Pacific Railroad expansion, the town has a rich cultural history and a downtown shaped by its historical character, with numerous historic buildings, including the monumental Templeton Feed and Grain silo building in the main street downtown.

The town also has a regional medical center with facilities that attract people from around the county, with a strong potential for expansion. Although the town is a major regional attraction, there are several vacant and underutilized parcels that provide opportunities for infill development and allow for the conservation of the open space around the community. Challenges for our class included: hesitation from the community toward diversifying housing options, high impact fees for development along Ramada Drive, and traffic along Vineyard Drive, Main Street and Las Tablas Road that impedes bicycle and pedestrian safety.

\section{The Planning Process}

\section{Existing Conditions}

The class began by compiling primary and secondary data and reviewing relevant studies, research, and reports by the County of San Luis Obispo. Detailed background information regarding the following five topics was gathered: population and housing, land use, environmental resources, circulation and noise, and community facilities. The students used site visits, discussions with County staff, community workshops, and relevant County documents to thoroughly address each topic; and to better understand opportunities and challenges for development in Templeton, the public's concerns, and their vision for their community.

\section{Public Outreach}

Besides on-street surveys and interviews, several community outreach events were held in order to guide the planning and design efforts. All meetings and interviews were conducted in Downtown Templeton at the Templeton Community Center. In the first Community Workshop 35 participants identified opportunities and challenges for development and generated an overall vision for the future of Templeton. The workshop was followed by a series of stakeholder interviews and a focus group meeting with local business owners, representatives from the Medical District, Peoples' SelfHelp Housing, Templeton Community Service District, and the Templeton Chamber of Commerce to ensure a variety of public opinions. A workshop was also held at Templeton 
industrial area and to provide continuity throughout the town. Commercial service use will be concentrated along Ramada Drive to capitalize on the freeway frontage off US Highway 101. The majority of this district is designated as two industrial categories: industrial with limitations, and industrial without limitations. Industrial with limitations is proposed behind commercial service use, while industrial without limitations is proposed on the east side of the area.

To identify an area suitable for the town's growth, the class conducted multiple studies addressing natural hazards, flooding and environmentally sensitive areas around Templeton, zooming in on a 380-acre area that was appropriate for development. Named the Vineyard Creek, the proposal provides spaces for a school expansion area, community center, transit center, gateway, trails and pedestrian paths. The concept focuses on mixed-use development and affordable housing, as well as large-lot homes overlooking a proposed golf course.

\section{Final Remarks}

The Templeton Community Planning Lab gave the students a new perspective on planning in rural towns. This experience exemplifies Cal Poly's "Learn by Doing" motto, allowing students to work collaboratively with community members to create a vision for the future of Templeton. Throughout the planning process, students were challenged to think outside the box and find innovative solutions for community concerns. The students' work successfully addresses the needs of the community and is a significant step toward updating the Templeton Community Plan.

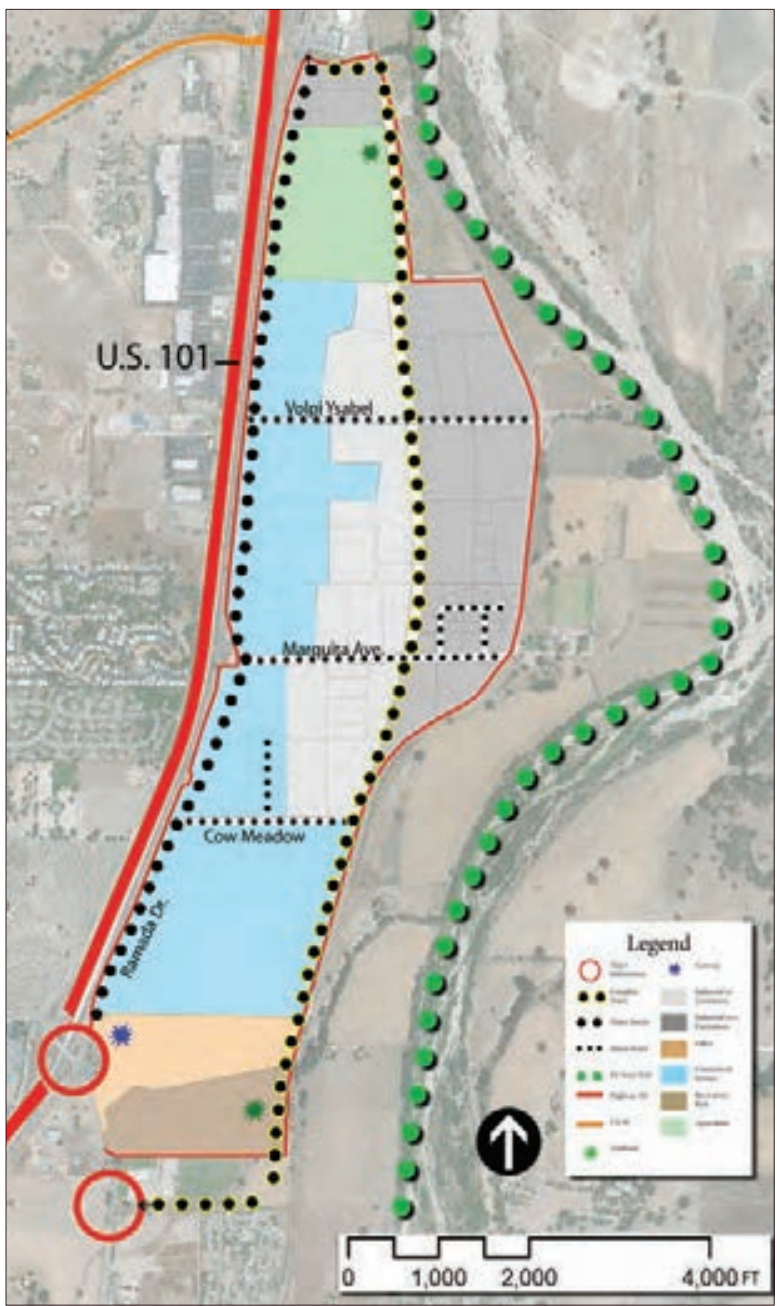

Figure 3: Final preferred alternative for the Ramada Drive Area Concept Plan.

Figure 5: The class in front of the community building where the visioning workshop was held.

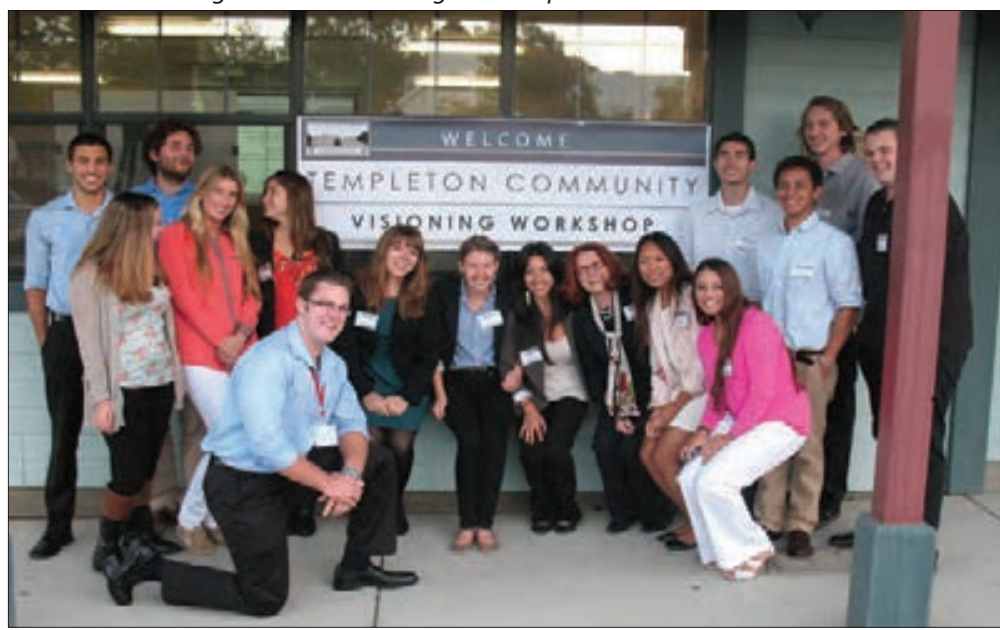

